\title{
Misleading Policy Messages Derived from the Period TFR: Should We Stop Using It?
}

\author{
Tomáš Sobotka, Wolfgang Lutz
}

\begin{abstract}
Discussions about fertility in developed countries refer almost exclusively to the period Total Fertility Rate (TFR). We argue that the use of this indicator frequently leads to incorrect interpretations of period fertility levels and trends, resulting in distorted policy conclusions and, potentially, in misguided policies. We illustrate this with four policy-relevant examples, drawn from contemporary Europe. These illustrations show that the TFR (a) inflates the presumed gap between fertility intentions and realised fertility, (b) erroneously suggests a significant fertility increase in many countries of Europe after the year 2000, (c) often exaggerates the level of immigrants' fertility and (d) frequently suggests that family-related policies which led to shorter birth spacing in fact brought an upward swing in fertility level. There seems to be no policy-relevant question for which the period TFR would be the indicator of choice to be preferred over other existing measures.
\end{abstract}

Keywords: Fertility measurement - Total fertility · Policies · Fertility intentions · Fertility timing $\cdot$ Tempo effect

\section{Introduction}

Demography has been in the headlines in Europe for many years and is being discussed in the highest policy circles. The European Commission has set up several bodies that discuss the "demographic challenge" which Commission President Barroso called one of the three main challenges for Europe, and in 2006 it published an official communication on the topic that was presented to the media under the catching title "Five ways to defuse the demographic time bomb" (European Commission 2006). The main policy paradigm conveyed in this communication as well as in speeches by family ministers around Europe is that young people want to have significantly more children than they actually can afford to have and that the role of policy is to help them meet their family size desires. The resolution of the European Parliament on the demographic future of Europe (21 February 2008) proposes that 
"the average birth rate in the European Union, which at 1.5 is abnormally low, is not a reflection of women's choice or of European citizens' actual aspirations for creating a family." As we will discuss below, this dominant and politically in many respects most convenient policy paradigm is largely based on an inappropriate use of the period Total Fertility Rate (TFR) which is compared with the cohort measure of desired family size as if it were itself a cohort measure of fertility. The same problem is found with another policy message that is being spread in Europe, namely the reversal of the declining fertility trends. Many politicians point at recent increases in the TFR as proof of their successful policies. In this study, we show that this trend often cannot be interpreted as a major turnaround in fertility because it is largely a consequence of the expected end of fertility postponement with government policies playing little role. Again, it is frequently the inappropriate use of the TFR that causes this misleading message.

Current public discussions about fertility trends and policies in developed countries almost exclusively refer to the period TFR which has become the ubiquitous fertility indicator of choice since the 1960s. It is commonly labeled as the "mean number of children per woman" by many demographers and statistical offices and, in consequence, also by journalists and politicians. This "synthetic cohort" interpretation has become "deeply engrained in demographic thinking" (Ní Bhrolcháin 2007: 44). In the public discourse relatively few references are made to cohort fertility as the adequate measure of fertility or to other indicators of period fertility that may better reflect changes in fertility trends. Likewise, little reference is made to trends in the absolute number of births, which after all directly determine the future size and age structure of the population. Although all demographers should be aware of the serious problems associated with calling the period TFR the "mean number of children per woman," a notion that only makes sense from a cohort perspective, there is hardly any public discussion about this. One important exception was a brief but heated public discussion in France in the early 1990s (see Keyfitz 1993 and a discussion on period fertility measures in Population 1994). Interestingly, this debate initially focused on the choice between period and cohort fertility measures and practically took for granted that the TFR represents the period fertility measure of choice. More recently the European Demographic Data Sheets (see VID 2010 for the latest one) have presented calculations of TFRs adjusted for "tempo effect" (i.e., the influence of changes in the timing of childbearing) along with traditional TFRs and cohort fertility measures in order to draw attention to this problem.

In discussing the use and usefulness of the period TFR this article partly relates to a recent work by Ní Bhrolcháin $(2007,2008)$ who distinguishes five purposes ("reasons") for which the TFR is being used and stresses that the choice of the fertility indicator should be determined by the analyst's objective. We go beyond this rather broad concept of measurement purposes and focus primarily on a policyrelevant analysis of fertility trends and the questions surrounding it. We believe that demographers are expected to address specific questions that have societal or policy relevance and communicate their research to broader public. For some of these questions (such as, how many school-age children can we expect in ten years) the most appropriate demographic measure is the absolute number of births 
(adjusted for child mortality and actual or expected migration), while for others (e.g. whether women have on average more children as a consequence of economic or political changes) measures of fertility level would provide the best answer. As we will discuss in the concluding section, the well-established TFR index does not give a satisfactory answer to such "real world" questions beyond the narrow arena of demographic modelling.

In the following we will try to demonstrate that the period TFR is a very problematic measure for assessing both the need for and the impact of policy changes and, more generally, for studying fertility trends in conjunction with selected social and economic trends. The excessive use of this problematic indicator, motivated in part by its wide availability for different countries and periods, can lead to erroneous conclusions. We will also address two natural follow-up questions (a) "Can we offer a better indicator of fertility level based on period information?", and, if the answer is affirmative, (b) "Is there any role left for the traditional period TFR?" Most of the article deals with the first question and compares the messages derived from the period TFR with those derived from three alternative measures of period fertility and from completed cohort fertility (labelled CTFR). The second question, which is more radical in its potential implications, is addressed in the concluding section.

The study first reiterates the increasingly recognised fact that the period TFR can diverge considerably and systematically from the CTFR of women having children in a given period and this divergence can stretch over long periods of time. Timing effects and compositional factors affecting the period TFR may be seen as factors that confound the link between fertility and policy. We present four examples where the period TFR is typically used as a criterion for an evaluation of the "underlying" level of fertility, often referred to as "fertility quantum"1 (Bongaarts/Feeney 1998; van Imhoff 2001). We discuss whether the period TFR provides adequate and useful information about fertility levels and trends and whether this evaluation changes when other fertility indicators are used instead of the conventional period TFR. These illustrations show that the TFR (a) inflates the presumed gap between fertility intentions and realised fertility, (b) erroneously suggests a significant fertility increase in many European countries after the year 2000, (c) often exaggerates the level of immigrants' fertility and (d) frequently suggests that family-related policies which led to shorter birth spacing in fact brought an upward swing in fertility level.

1 While there is no generally recognized definition of "fertility quantum", in a period perspective it is often understood to reflect the fertility level that is undistorted by confounding factors like changing timing (tempo) of childbearing or changing parity composition of the female population. From a cohort perspective, the completed fertility rate is an unambiguous and undistorted indicator of fertility quantum. 


\section{Problems with the period TFR}

An increasing number of studies have demonstrated that the period TFR is a questionable measure of the level (quantum) of period fertility. It controls neither for the parity distribution of women nor for duration since the last birth, which are the key determining factors of reproductive behaviour (Rallu/Toulemon 1994a and Population 1994). Even more important, it is very sensitive to changes in the timing of childbearing, which inflate the TFR when women have children at progressively earlier ages and depress it when they postpone childbearing to later reproductive ages (e.g. Ryder 1990; Bongaarts/Feeney 1998; Bongaarts 2002; Sobotka 2004a). The latter situation has been typical for most developed countries since the early 1970s, when a long-term trend towards delayed parenthood started in western and northern Europe as well as in Canada, Japan and the United States Kohler et al. 2002; Sobotka 2004b). Various estimates suggested that without this shift in the timing of childbearing period TFR in the European Union would have been by 0.2 to 0.3 higher in the late 1990s and early 2000s (Lutz et al. 2003; Sobotka 2004a), although this tempo effect was strongly regionally differentiated (Bongaarts 2002; Frejkal Sobotka 2008; VID 2010).

As a result, the period TFR considerably diverged from the completed cohort fertility of women who were in their prime childbearing ages in a given period. Such a mismatch is not problematic for short-term fluctuations, when period fertility measures should reflect actual ups and downs in birth rates that may not affect ultimate cohort fertility trends (Ní Bhrolcháin 1992). However, this disagreement becomes problematic once the period TFR differs systematically from the corresponding CTFR for two or three decades, as it has happened across much of the developed world. Figure 1 gives an illustration of this divergence for Denmark, where the gap between the period TFR and roughly corresponding CTFR averaged 0.26 in the period of 1970-1994 (the corresponding CTFR cannot be computed yet for the younger cohorts).

Such a long-term divergence implies that the period TFR provides incorrect signals about the levels and trends of fertility and, by extension, also about the longterm prospects of population replacement and population growth in the absence of migration. Such "incorrect signals" about fertility levels also have policy relevance as they may provide arguments that exaggerate the problem of "extremely low" fertility as well as the prospects of future population decline. Since the late 1970s, numerous statements and declarations of European politicians and parliaments about "insufficient birth rate" in Europe were firmly based on the observations of trends in the period TFR (see European Parliament 1984 and 2008). For example, the former Commissioner for Employment and Social Affairs has proclaimed that " [T] he fertility level for the EU as a whole is about 1.5 children per woman, well below the estimated replacement level of 2.1 ," noting that some countries with "fertility rates of 1.3 children or less [...] face dramatic population decreases" (Špidla 2007: 2). Also these statements are grounded in the period TFR as there is no EU country at present where women born around 1970 are heading toward a completed fertility rate of 1.4 or below. 
Fig. 1: $\quad$ Period TFR (1965-2008) and CTFR (women born in 1937-1967) in Denmark

Period (cohort) total fertility rate

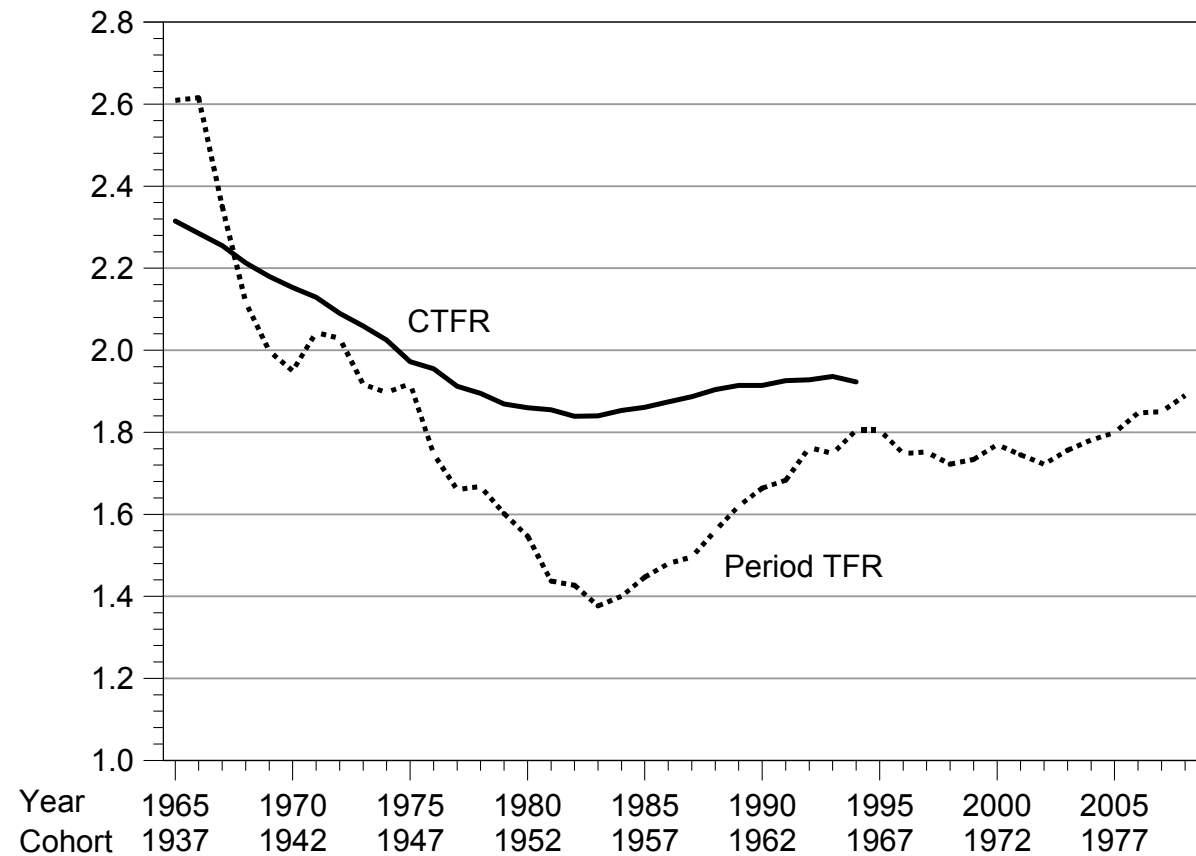

Notes: Data on CTFR are based on two neighbouring cohorts; e.g. cohort 1937 refers to a cohort born in 1937-1938. A small fraction of the CTFR is estimated for women born in 1960-1967. Period data are compared with the cohort data for women born 27-28 years earlier; this distance corresponds approximately to the mean age at childbearing in 1968-1994.

Source: Council of Europe (2006) and Eurostat $(2008,2009)$ for the period TFR; Statistics Denmark (2007) (Tab. 2.5 and 2.6) for the CTFR.

As an alternative to the period TFR, we use the following range of indicators of period fertility:

- (a) tempo-adjusted period TFR*s, proposed by Bongaarts and Feeney (1998), which are based on birth-order specific correction in the conventional TFRs that reflect the changes in the mean ages of fertility schedule;

- (b) an age and parity-specific index of fertility, PATFR (e.g. Rallu/Toulemon 1994a) which is based on a fertility table that controls for age and parity distribution of women of reproductive age

- (c) its variant adjusted for tempo and variance effects, PATFR* (Koh/er/Ortega 2002).

We also employ completed cohort fertility. The choice of these indicators is driven in part by their suitability to address a given issue and in part by data availability. 
We are well aware of the shortcomings of the Bongaarts-Feeney adjustment, such as its simplified underlying assumption about the constant shape of fertility schedule, its lack of controlling for changes in the parity distribution of the female population and its relatively strong fluctuations over time (van Imhoff 2001; Schoen 2004). However, we use it alongside the adjusted PATFR* for the reason of data availability and also because in most cases, it gives similar results to the other fertility adjustment methods. We do not dispose for a number of countries with potentially more appropriate indexes based on parity and duration since the last birth, which largely eliminate the need for tempo adjustment (Sobotka et al. 2005; Ní Bhrolcháin 2008). We provide a brief description of the indicators used in the Appendix.

\section{Example 1: The assumed gap between desired and actual fertility}

Surveys on fertility ideals and intentions frequently indicate that despite the decline in fertility rates well below the replacement-level threshold, both mean ideal and desired family sizes in most countries of Europe remain at or above two children per woman (e.g. Testa 2007). The period TFR has been repeatedly used to estimate this gap, suggesting a huge aggregate discrepancy between actual and intended fertility (see also Bongaarts 2008), often in the order of 0.5-0.8 children per woman (e.g. Chesnais 2000). A recent OECD analysis (OECD 2007: 36) posits that "the gaps between desired and actual fertility rates have increased over the past ten to twenty years" and suggests that these gaps are largest in countries where fertility rates are lowest. Several distinct explanations of this discrepancy have been proposed, among which institutional and structural constraints to childbearing and childrearing (McDonald 2006) are frequently taken as evidence of a need for policy action (European Commission 2005; McDonald 2006).

The issue has been empirically illustrated by Lutz (2007); this illustration is further elaborated in Table 1. It combines four different fertility and family size indicators in major regions of the European Union (EU). The first column lists the personal ideal family size as collected in the Eurobarometer survey in 2006 for women aged 25-39 (Testa 2006). The second column, also based on Eurobarometer, gives the total intended family size for the same group of women. It combines the number of children already born with the number of children women intend to have in the future. This second measure constitutes a more realistic predictor of fertility than ideal family size, since it takes into account expected obstacles and difficulties in realising their fertility ideals and desires. However, a comparison between these two measures from the same survey shows that there is only a small difference between them, 0.15 children per woman for the whole EU.

The third and fourth columns in Table 1 list the TFR for 2006 and the BongaartsFeeney (1998) tempo-adjusted TFR* for $2005-2007$ as published in the European Demographic Data Sheet (VID 2010). The difference between the conventional TFR and the ideal family size (Gap 1 in Column 5 ) is indeed substantial - more than half a child in all regions - and reaches 0.7 children for the EU. However, the two figures used to construct this gap are not comparable because they measure very different things, one cohort ideals and the other tempo-distorted period fertility. 
Tab. 1: Ideal and intended family size and the period TFR of women in various regions of the EU in 2006 and different ways to calculate the 'gap' between ideal (intended) and actual fertility

\begin{tabular}{|c|c|c|c|c|c|c|c|}
\hline & $\begin{array}{c}\text { (1) } \\
\text { Personal } \\
\text { ideal } \\
\text { family size }\end{array}$ & $\begin{array}{c}\text { (2) } \\
\text { Actual + } \\
\text { intended } \\
\text { family size }\end{array}$ & $\begin{array}{c}\text { (3) } \\
\text { TFR }\end{array}$ & $\begin{array}{c}\text { (4) } \\
\text { Tempo } \\
\text { adjusted } \\
\text { TFR* }\end{array}$ & $\begin{array}{c}(5) \\
\text { Gap } 1 \\
(1)-(3)\end{array}$ & $\begin{array}{c}(6) \\
\text { Gap } 2 \\
(1)-(4)\end{array}$ & $\begin{array}{c}\text { (7) } \\
\text { Gap } 3 \\
(2)-(4)\end{array}$ \\
\hline Western Europe & 2.44 & 2.36 & 1.88 & 2.05 & 0.56 & 0.39 & 0.31 \\
\hline Northern Europe & 2.57 & 2.35 & 1.85 & 1.95 & 0.72 & 0.62 & 0.41 \\
\hline Southern Europe & 2.08 & 1.81 & 1.37 & 1.46 & 0.71 & 0.61 & 0.35 \\
\hline Austria + Germany & 2.07 & 1.88 & 1.34 & 1.62 & 0.74 & 0.45 & 0.25 \\
\hline \multicolumn{8}{|l|}{ Central-Eastern } \\
\hline Europe & 2.09 & 2.04 & 1.31 & 1.60 & 0.79 & 0.50 & 0.44 \\
\hline EU-27 & 2.21 & 2.06 & 1.53 & 1.72 & 0.68 & 0.49 & 0.34 \\
\hline
\end{tabular}

Note: Data are weighted by population size of countries in given regions.

Source: Columns (1) and (2): Eurobarometer 2006 data analysed by Testa (2006). (3) and (4): VID 2010

If one wishes to compare the ideal family size to a period fertility measure, then tempo-adjusted TFR* would be more appropriate. As Column 6 shows, the gap between those two indexes (Gap 2) becomes smaller and reaches 0.5 for the whole EU. The last column finally indicates a third kind of gap, namely that between the intended family size and the adjusted TFR*. This third gap is the smallest of all, ranging around 0.3-0.4 for different regions and reaching 0.34 for the $\mathrm{EU}$; it represents about half of Gap 1.

These data make the population policy rationale aiming at helping couples reduce the presumed gap between desires and reality look much less convincing: Does this imply that governments have little reason to take action in countries like Austria and Germany that have a relatively small aggregate gap, but in the view of their governments undesirably low fertility rates? Probably it does not. On the other hand, high-fertility countries of northern Europe have a somewhat larger gap when measured this way. Should governments be more active in countries which have a higher overall level of fertility? Probably they should not. In fact, Nordic countries, which have similar "fertility gaps" as other countries, are often cited as examples of what kind of policies governments in low-fertility countries should introduce in order to make it easier for couples to combine work and family. Hence the policy paradigm based on the presumed "unmet need for children" is problematic on both counts; to some extent it reflects wishful thinking of policy makers and their implicit pronatalism.

While this analysis based on the Eurobarometer data (Testa 2006; Lutz 2007) clearly illustrates the issue, there are some justified doubts about the validity and representativeness of this type of data from an opinion survey with limited sam- 
ple size (typically around 130 female respondents aged 25-39 per country), which vastly increases the potential margin of error (Testa 2006). Moreover, comparisons between intentions and period fertility rates are problematic. They relate the cohort intentions for children to be born in the future to the period measures of recent fertility behaviour. A comparison of intended fertility among selected cohorts of women, expressed when they were in their prime reproductive years, with their final completed fertility, is methodologically preferable. Hence, we also present a more in-depth analysis, using data from comparatively large surveys from Austria and England and Wales. We compare the intended family size, which best reflects women's and couples' long-term childbearing plans with their completed cohort fertility.

In fact, cohort analysis leads to conclusions that are very similar to the comparison based on adjusted period measures discussed above. In England and Wales different cohorts of women who were interviewed at age 27-29 about their fertility plans expressed the mean intended family size (MIFS) to be about 0.3-0.4 higher than the period TFR at that time (see Smallwood/Jefferies 2003 for trends in MIFS over time). However, the eventual gap between their intentions and the ultimately achieved fertility level was reduced by about half and typically reached only 0.1-0.2 (Tab. 2).

Similarly, in Austria the period TFR also gives an exaggerated picture of the extent of unrealised fertility desires. At the time Austrian women reach their typical

Tab. 2: Difference between the mean intended family size (MIFS), period TFR and CTFR in England and Wales (women aged 27-29, period 1979-1996)

\begin{tabular}{llccccc}
\hline Years & Cohort & $(1)$ & $\begin{array}{c}\text { Meriod } \\
\text { TFR } \\
(2)\end{array}$ & Gap 1 & CTFR & Gap 2 \\
\hline $1979-81$ & around 1952 & 2.12 & 1.84 & 0.28 & 2.05 & 0.07 \\
$1982-84$ & around 1955 & 2.16 & 1.76 & 0.40 & 2.02 & 0.14 \\
$1985-87$ & around 1958 & 2.16 & 1.79 & 0.37 & 1.99 & 0.17 \\
$1988-90$ & around 1961 & 2.20 & 1.82 & 0.38 & 1.96 & 0.24 \\
$1991-93$ & around 1964 & 2.09 & 1.79 & 0.30 & 1.92 (est) & 0.17 \\
$1994-96$ & around 1967 & 2.14 & 1.74 & 0.40 & 1.91 (est.) & 0.23 \\
Average & & 2.15 & 1.79 & 0.36 & 1.98 & 0.17 \\
\hline
\end{tabular}

Notes: MIFS refers to the mean intended family size among women aged 27-29; answers of undecided respondents were ignored (see Smal/wood/Jefferies 2003 for alternative estimates of the MIFS based on different assumptions about uncertain respondents).

Data on the CTFR are partly estimated for cohorts born around 1964 and 1967.

Source: MIFS: Smal/wood/Jefferies 2003, Tab. 1. CTFR: ONS 2007, Tab. 10.2: 56-57. 
age at childbearing the gap between their mean reproductive desires and the contemporary level of TFR commonly widens to 0.4-0.5. However, a comparison of fertility intentions at younger ages with completed fertility shows that the intentionbehaviour gap becomes substantially smaller, specifically, around 0.15 in the case of the cohorts 1955-60 and 1966-70 analysed in Figure 2. This finding is again surprisingly consistent with the conclusions based on period-based tempo-adjusted measures of fertility. Our detailed investigation of period fertility rates and fertility intentions in the Czech Republic after 1990, when the country underwent a dramatic fall in total fertility, also yields similar conclusions. In 1997, when the period TFR dropped to 1.18 , the gap between the mean intended family size and the period TFR surpassed 0.8 , whereas the tempo-adjusted TFR* indicated a much smaller gap of 0.3 (Tab. 2 in Sobotka/Lutz 2009: 14 ).

Fig. 2: Differences between mean intended family size (MIFS), period TFR and CTFR, Austrian women aged 25-30 (years 1986 and 1996, cohorts 1956-1960 and 1966-1970)

Intended family size, TFR and

realised family size

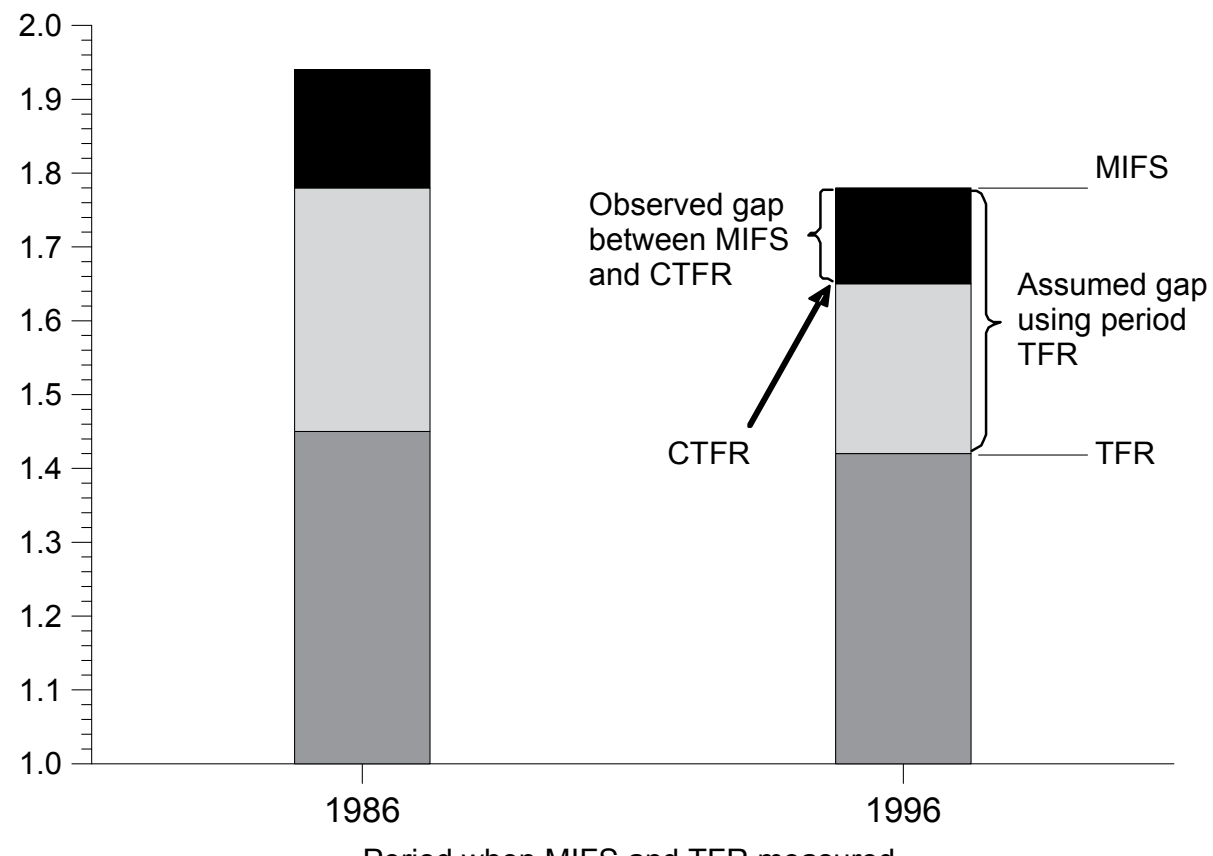

Period when MIFS and TFR measured

Notes: MIFS refers to the medium variant estimate of the mean desired family size among women aged 25-30 (see Sobotka 2009).

Data on the CTFR are partly estimated for the cohorts born in 1966-1970.

Source: Sobotka's (2009) computation from Microcensus (1986 and 1996) data 
All in all, period measures of fertility that are less distorted by changes in fertility timing than the period TFR as well as the ultimately achieved cohort fertility show that the gap between intended and realised fertility is grossly exaggerated when analysed with the period TFR. If the intentions data were further adjusted for some factors that are mostly outside the reach of government policies, such as having no suitable partner, disagreement between partners or poor health status, the presumed gap might become entirely erased. A French survey analysed by Toulemon and Leridon (1999) revealed that when women who had never lived with a partner were disregarded, the mean ideal family size at ages 25-35 (2.21) corresponded remarkably well with the eventually achieved mean family size (2.23) among women born in 1950-65.

Caution needs to be taken when interpreting these findings. The proper measurement of intentions and their correspondence with realised fertility is not settled just by properly accounting for tempo effect and remains challenging even when more appropriate indicators than the period TFR are used. Aggregate consistency does not mean that most individuals achieve their intended family size. Fertility intentions are often uncertain (Westoff/Ryder 1977; Morgan 1981; Sobotka 2009) and subject to changes and revisions during the life course (Quesne/-Vallée/Morgan 2004; Liefbroer 2009). The aggregate results represent an outcome of both under-achieving and over-achieving of the initial targets among individual women. Furthermore, the concepts of intended and ideal family size can both be criticised. The definition of intended fertility adds the number of children already born to those still intended, which makes any unplanned births in the past part of the total intended family size. Even in European countries with high contraceptive use and broad access to abortion, unplanned births push both the intended and realised fertility rate slightly upwards. This problem is avoided by the more hypothetical personal ideal family size which, on the other hand, is more detached from individual circumstances affecting reproductive behaviour, including infertility, and thus also harder to interpret.

\section{Example 2: Recent increase in the period TFR in Europe}

Since the late 1990s many countries of Europe have recorded a notable increase in the period total fertility. In Belgium, Bulgaria, the Czech Republic, Estonia, France, Ireland, Latvia, Russia, Slovenia, Spain, Sweden, United Kingdom and Ukraine the TFR increased by more than 0.2 between 2000 and 2008 (Goldstein et al. 2009). This has been generally interpreted as a welcome sign, indicating the much-needed reversal of the previous long-standing trend of declining period fertility rates, which in many countries of Europe had brought the TFR to "lowest-low" levels of 1.3 or below (Kohler et al. 2002). Some governments have proudly attributed this trend to their policy action and a leading newspaper in Germany, Die Zeit, commented a tiny increase in the number of births in 2007 with the cheerful pronouncement "politics work!" (Gaschke 2009). However, an alternative explanation provides a different perspective on the recent rise in the period TFR. It is possible that much of the recent increase in the period TFR in European countries can be attributed to the slowing down or ending of fertility postponement (Goldstein et al. 2009, Bongaarts/ 
Sobotka 2010). We look at fertility changes in two countries - the Czech Republic and Spain - which have experienced a substantial rise in the period TFR since the late 1990s and for which we could compute alternative indicators of period fertility that are less affected by the tempo effect. A systematic analysis of the role of tempo effects in the recent TFR increase is provided in recent studies by Goldstein et al. (2009) and Bongaarts and Sobotka (2010).

Spain experienced a steep and continuous decline in the period TFR between 1976 and 1996, when it reached a record-low level of 1.17. At the same time the alternative tempo-adjusted indicators of period fertility also displayed an almost continuous fall, although at somewhat higher levels, suggesting that the fertility "quantum" fell in parallel with the period TFR (Fig. 3). After 1996 the TFR first stabilised and then started rising, peaking at 1.46 in 2008 (e.g. Delgado et al. 2008). However, the tempo-adjusted fertility indicators give another perspective on recent fertility "reversal". First, they suggest that fertility was declining until 2000, i.e. during the time when the TFR had stabilised and started to increase. Subsequently, these indicators essentially show a stabilisation in period fertility. In effect, there was convergence between the period TFR and the adjusted period fertility measures around 2005 when the increase in the mean age at first birth stopped. This is a nice illustration of the expected consequence of the ending of the tempo effect.

A different story is depicted in Figure 3 for the Czech Republic. A massive postponement of childbearing after the collapse of the state-socialist system has taken place there since the early 1990s, bringing a pronounced rise in the mean age at first birth (Sobotka et al. 2008). In parallel, the TFR had fallen to the level of 1.13 in 1999 and then started a gradual recovery since the early 2000s, reaching 1.50 in 2008. The adjusted TFR* as well as the age- and parity-specific index of fertility, the PATFR $^{*}$, adjusted for tempo effects (Koh/er/Ortega's 2002 adjustment, see Appendix) fell much less precipitously over the 1990s to a level around 1.6 in 1998 . This divergence between the ordinary TFR and the tempo-adjusted indicators suggests that a substantial part of the steep drop in the TFR could be attributed to the tempo effect. In contrast to Spain, a rise in the TFR in the early 2000s occurred in tandem with an increase in the adjusted TFR*, albeit a less intensive one. It is likely that the continuing rise in the ordinary TFR will bring a gradual convergence between different fertility measures in the future, in reaction to a slowing down of fertility postponement.

In these two cases, and many others not discussed here (e.g. Goldstein et al. 2009), the adjusted indicators offer a different interpretation of recent fertility trends than the ordinary TFR. Whereas the TFR provides an impression of a substantial increase in fertility rates, the adjusted indicators often show that this increase was almost entirely (Spain) or largely (Czech Republic) driven by the diminishing tempo distortion.

This explanation is particularly pertinent for first births, for which the recent rise in the TFR was most clearly manifested. To illustrate this point, we compare the ordinary TFR for birth order 1 in Spain with the period fertility index based on agespecific probabilities of having the first child computed for childless women (PATFR), which is markedly less affected by the tempo effect (Sobotka 2004b), and by its 
Fig. 3: $\quad$ Period TFR, TFR*, PATFR* index for total births and mean age at first birth (MAFB) in Spain (1980-2007) and the Czech Republic (1988-2008)
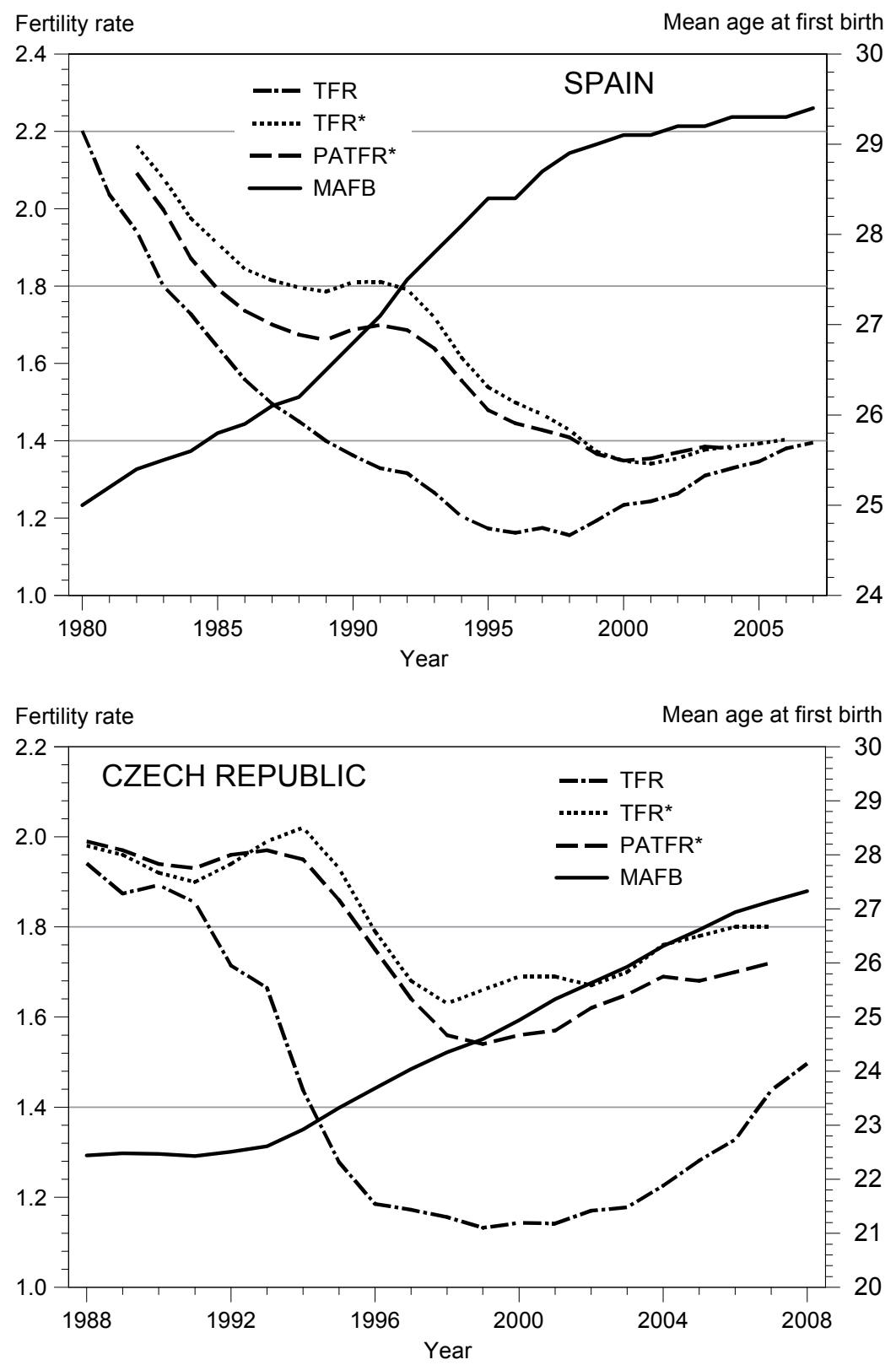

Notes: For adjusted TFR* and PATFR* average values for 3-year periods centred on a given year are shown.

Source: Authors' computations based on Eurostat (2003, 2008 and 2010), INE (2009) and the data provided by the Czech Statistical Office. 
adjusted variant (PATFR ${ }^{*}$ ) computed using a simplified version (Sobotka 2004b: 94) of Kohler and Ortega's (2002) adjustment (see Appendix; see Sobotka/Lutz 2009 for an additional example of first birth trends in the Czech Republic). ${ }^{2}$

These three indexes provide contrasting impressions about the trends and levels of first-birth rates. Between 1980, when they stood at around 0.9 (suggesting $10 \%$ childlessness) and 2005-2007, when they generally converged, although at a lower level around 0.8, the first-order TFR had dramatically fallen to 0.57 in 1996 and subsequently rose by a third during the next decade (Fig. 4). In contrast, the first-order PATFR* depicts a gradual fall between 1980 and 1996 followed by a stabilisation. In other words, first-birth intensity did not rise after 1996 and almost all the increase in first-order TFR in Spain can be explained by a mechanical effect of a steep increase in the number of childless women at higher childbearing ages, when first-birth intensities remained relatively high and stable. This effect is not accounted for in order-specific TFR, which does not control for shifts in the parity distribution among women. Finally, when taking both tempo- and parity-composition effects into account the adjusted PATFR* ${ }^{*}$ suggests that first-birth intensities actually declined between 1996 and 2006.

In sum, during the recent period the ordinary TFR usually indicates a larger magnitude of change, especially for first births, than fertility indicators which control for parity, duration, tempo effect, or at least some of these potentially distorting factors. Most of the TFR shifts can be explained by an increase in first-order TFR and, in turn, most of the increase in first-order TFR can be explained by a diminishing tempo effect coupled with an increase in the number of childless women at later childbearing ages. The often dramatic reversals in first-order TFR can be seen as a product of two distinct phases of first-birth postponement. During the first phase, many cohorts of women delayed their entry into motherhood, causing a decline in the TFR. In a second phase, however, they began realising their "postponed" childbearing, contributing thus to the recuperation of fertility rates at higher reproductive ages, which pushed the ordinary TFR upwards. The analysis of first-birth rates, where the cycle of fertility delay and subsequent recuperation is most apparent and fuels large shifts in the first-order TFR, best exposes the weaknesses of the conventional period total fertility when it is used as a measure of childbearing intensity or as a synthetic cohort indicator of the "number of children per woman".

\section{Example 3: TFR as a problematic measure of the fertility of immigrants}

Fertility of immigrants, when measured by the period TFR, is subject to yet another type of distortion linked to the endogeneity of migration for fertility. Immigrant women, especially when migration took place for the purpose of family formation,

2 We do not employ the Bongaarts-Feeney TFR* in the analysis of first births, as this indicator is rather unstable when analysed by birth order. This issue has been addressed by Bongaarts and Feeney (2006) who proposed parity-specific fertility adjustment (see also Bongaarts/Sobotka 2010). However, the inclusion of this new indicator would "burden" our study with yet another index of fertility and we decided not to use it here. 
Fig. 4: Period TFR, PATFR and PATFR* for first births, Spain 1980-2007

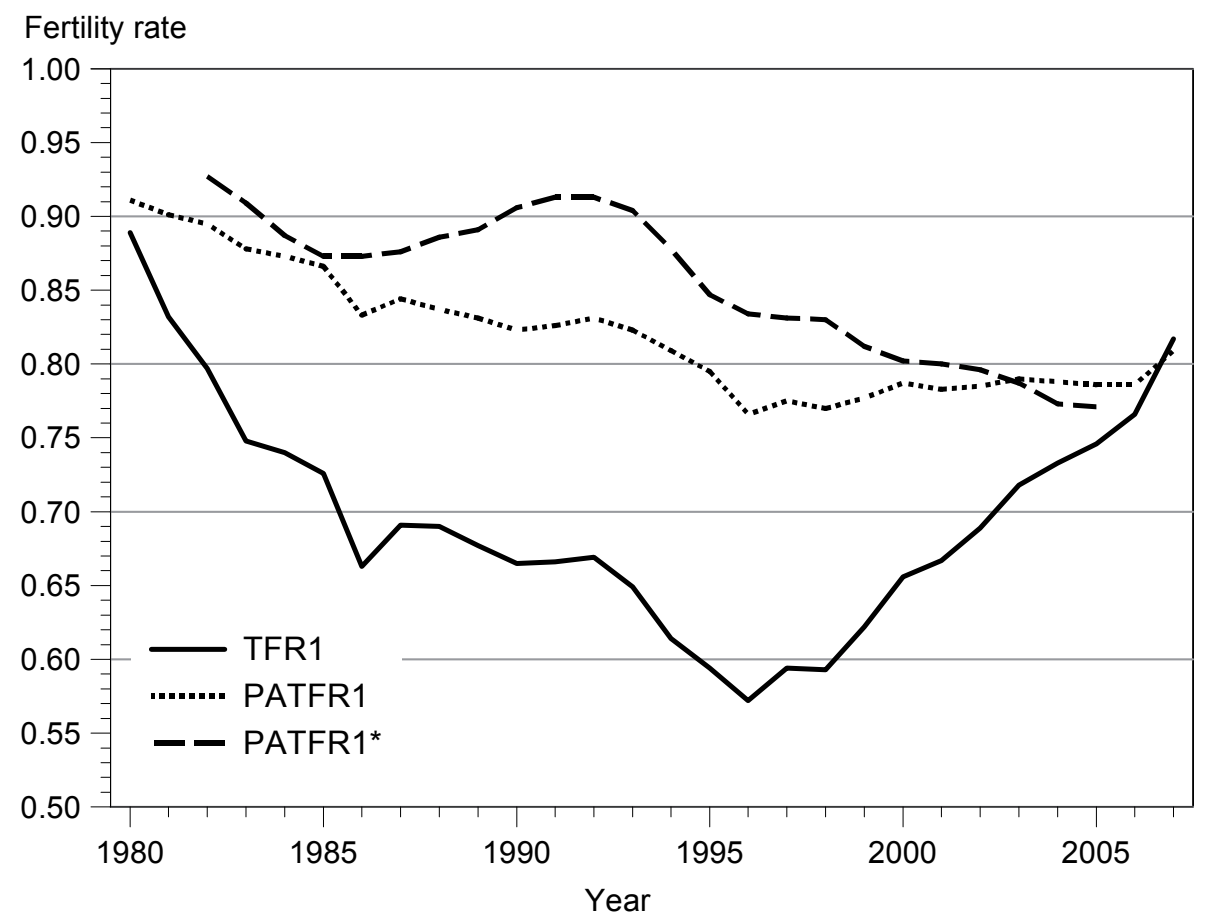

Notes: For adjusted TFR* and PATFR* average values for 3 -year periods centred on a given year are shown.

Source: Authors' computations based on Eurostat (2003, 2008, and 2010), INE (2008 and 2009).

typically show elevated fertility rates during the first years after their arrival (e.g. Alders 2000; Østby 2002; Andersson 2004; Toulemon/Mazuy 2004). Consequently, their fertility rates are often more closely related to the duration of their stay rather than to their age. The total fertility, which takes age as the indexing variable of fertility, may therefore be strongly biased by the size of immigration streams: Even when fertility rates computed by the duration of stay in the country remain stable, increased migration would bring an inflated TFR by increasing the number of migrant women with short durations of stay, when their fertility rates are highest. Thus, the TFR computed for immigrants usually exaggerates their fertility quantum during periods of high immigration.

This distortion becomes yet more serious when the data on births are recorded for women with foreign nationality only, rather than for all women of immigrant origin. As many immigrants undergo a process of naturalisation when they stay in a country for many years and at some point become classified as nationals, foreigners frequently constitute a select group of migrants with relatively short duration of stay and thus also with elevated period total fertility. Therefore, some researchers 
have argued that the period TFR cannot serve as a reliable indicator of the level of immigrants' fertility (Andersson 2004; Toulemon 2004). The selectivity of foreignnationality migrants and the methodological shortcomings of the TFR may explain why several European countries record the TFR for foreign women as high as 3.0 and above (e.g. Sobotka 2008). For instance, the TFR for foreign women in France in 2005 was estimated at 3.29 as compared with 1.80 for women with French nationality (Héran/Pison 2007).

Not much research has been conducted yet to correct for this type of distortion in the TFR. Alternative estimates of migrant women's TFR for France controlling for age at entry and duration of stay (Toulemon 2004; Toulemon/Mazuy 2004) constitute the main exception. For 1991-1998 this alternative estimate reduced the TFR of immigrant women in France from 2.50 (estimated by using the conventional TFR) to 2.16. Thus, the "excess" fertility of immigrant women in France as compared to native women, falls to about one half of its estimated level, from 0.85 to 0.46 when a more appropriate fertility indicator is used (Toulemon 2004: 4).

\section{Example 4: Changes in family policies and shifts in TFR}

So far our analysis has not referred explicitly to family policies. There is an increasing body of evidence that family-related policies can stimulate distinct swings in total fertility, which are often primarily induced by changes in fertility timing and spacing rather than by an increase in the underlying fertility quantum (Gauthier 2007). Specifically, policies may stimulate earlier entry into parenthood or, which is more frequently the case, a faster progression to higher-order births.

The effects of changes in family policies on the timing of births have been documented for many European countries. For instance, Sweden constitutes a wellstudied example of a sudden upswing in second- and third-birth rates at short birth intervals. This upswing followed two extensions of parental leave, which granted a continuous provision of paid parental leave benefit amounting to $80 \%$ of their previous salary (90\% until 1994) to women who had another child within 24 months from 1980 and 30 months from 1986 (e.g. Hoem 1990; Andersson et al. 2006; Neyer/ Andersson 2008). This regulation, which became known as "speed premium", has led to a shortening of birth intervals and contributed to a distinct upward swing in period TFR in the late 1980s, as many parents found it manageable to have children closely spaced to take advantage of the continuous benefit (Hoem 1990).

Less well-known are the effects of policy changes introduced in Russia since 1982. These policies extended the period of maternity leave and, more importantly, they also extended the options for mothers to take child care leave until the child reached age 3 (see Zakharov 2006 and 2008; note that unlike in Sweden child care leave compensation remained low in Russia). Following this new regulation, the TFR in Russia increased from 1.88 in 1981 to 2.09 in 1983 and, after a short pause, to 2.23 in 1987 (Council of Europe 2006). However, what looks like a successful policy intervention that brought about a desired increase in fertility was mostly an indirect effect of a change in the timing of childbearing, bringing a temporary boost to the period TFR. The mean age at first birth slightly declined, but the most pronounced 
effect was recorded for women with one child, who were giving birth to their second child at considerably shorter intervals. In a period perspective, this second-birth interval fell from around 5.5 to 3.5 years between the mid-1970s and the mid-1980s (Zakharov 2008, Fig. 5: 928). Although second children were born much "faster" than before, especially among women born in the late 1950s and the early 1960s, Zakharov (2008: 927) did not detect any increase in their second birth progression rate. He concludes that "the demographic effect of the policy did not manifest itself in an increase in average family size in any major social groups."

However, not only the period TFR is very sensitive to changes in the timing of childbearing. Changes in birth intervals, which are frequent by-products of family policy changes, also affect period parity progression rates (PPRs), computed from duration-specific fertility rates. Breton and Prioux's (2005) detailed analysis of shifts in third-birth rates in France in the 1970s to 1990s reveal that third-birth PPRs have fluctuated in parallel with an introduction of family policies explicitly aimed at promoting third births (set up in 1978-1980 and again in 1985-87) as well as with the scaling-down of those measures in 1982. As in the previous two cases, these policies had primarily led to the temporary compression of birth intervals - in this case between the second and the third birth - and had only a limited effect on cohort fertility rates (Breton/Prioux 2005: 423; cohorts were defined as parity cohorts which measure progression rates to third birth among women having a second birth in a given year).

\section{Discussion and conclusions}

This study has discussed four examples of different situations where the use of the period TFR results in erroneous readings of the levels and trends of period fertility, which in turn may lead to incorrect policy conclusions and, potentially, to misguided policies. We have focused prominently on the influence of tempo distortions that have considerably affected levels and trends in the period TFR across Europe since the early 1970 s.

Our first example makes it clear that the popular and politically convenient policy rationale according to which governments should only try to help couples fill the gap between their desired and actual family size is ambiguous and often not very significant in terms of quantity. We arrive at the same conclusion when using adjusted period measures as well as when using the more appropriate cohort comparison of fertility intentions among women of reproductive age and their later reproductive outcomes. A much smaller aggregate difference between intended and realised fertility - typically about a half of the difference estimated from the period TFR - can be more easily explained by biological and social obstacles to childbearing (Bongaarts 2008) that are largely outside the scope of policy influences, such as poor health, infertility, or an inability to find a suitable partner.

Our second example reflects upon the most widely documented distortion in the period TFR - its sensitivity to changes in the timing of childbearing. We show that the period TFR may suggest too low fertility levels and subsequently signal a trend 
reversal and a substantial increase in fertility where other indicators show stagnation or even a slight downward trend (the example of first births in Spain). The difference between the period TFR and the more appropriate measures of period or cohort fertility level may be of major magnitude, potentially leading to a gross misinterpretation of fertility in a country (the examples of the Czech Republic and Denmark). Our analysis indicates that most of the recent increase in the period TFR has been driven by the rise in the TFR for first births, which can in turn be largely attributed to the diminishing first-birth postponement combined with a previous increase in the number of childless women at later childbearing ages (see also Goldstein et al. 2009). This finding has an important policy corollary: while the rising TFR may be interpreted by some governments and politicians as proving the positive effects of their social or family policies on fertility, our findings leave much less space for such a cheerful interpretation.

Our third example draws on the existing research on fertility of immigrant women. The fact that the TFR often distorts the picture of immigrants' fertility may potentially lead to ill-informed policy efforts addressing the presumably high difference between fertility of migrant and native-born women. Our fourth example turns to policy effects themselves. Many fertility-related policies primarily affect the timing of childbearing and as a result they also bring a temporary shift in the period TFR without shaping cohort fertility trends. This shift, caused mostly by the tempo effect, may please policymakers who are likely to incorrectly interpret it as a welcome sign of the turnaround in fertility rates, following the new policy measures.

Let us now turn to the second question mentioned in the introduction, namely whether there is any role left for the traditional period TFR. We have presented clear evidence that it may grossly distort any policy-relevant analysis. Does this imply that the use of period TFR should be entirely abandoned? On a theoretical level the answer essentially depends on whether or not the period TFR adequately measures and describes some process that can be meaningfully interpreted and that other fertility indicators do not capture in the same way (see also Ní Bhrolcháin 2007 and 2008). In the spectrum of summary indicators of natality and period fertility that ranges from the absolute number of births per year (influenced by population size, age structure, parity and birth interval distribution of women, as well as tempo effects) at one end to parity, age and duration-specific indexes on the other, the period TFR occupies an odd in-between position. It adjusts for population size and age structure but not for parity and birth intervals distribution or tempo effect. The decisive point then is whether there are any meaningful questions for which the answer would be provided by an indicator which only adjusts for age structure and not for other potentially important factors. By extension, this question also pertains to the issue of the factors that should be controlled for in an ideal fertility index of choice (see Population 1994). In theory, such a list can be extended to include factors like infertility, partnership status of women, or even their education status or fertility preferences (only women wishing to have a child in a given year would be included in at-risk population). However, lack of data, measurement and computational problems as well as interpretation difficulties imply that the list of characteristics to be 
controlled for in any useful fertility index should be limited to the most essential ones.

We could not come up with a policy-relevant question for which the period TFR would be our indicator of choice. All questions that were considered in the end either related to age structure, cohort size or population growth for which the simple natality indicators provide the adequate answer or pertained to childbearing behaviour, such as the question whether a certain policy has led to a higher fertility rate. The latter question, in order to be adequately addressed, requires controlling for parity or duration composition and tempo effect or turning to a cohort fertility analysis. The only instances for which we could identify a role for the period TFR is the artificial realm of models of age-structured population dynamics constructed by demographers. And of course, in this realm the TFR still provides the best answer to the question "Did the TFR increase?" And since the TFR is such an established measure, a lot of people will keep asking this question.

The influence of the changing timing of childbearing on the period TFR is in our view particularly pertinent to current policy debates and proposals. Although the efforts to eliminate the tempo effect from period fertility measures remain by definition imperfect and subject to criticism, they are in our view worth undertaking. Policy-relevant questions are usually concerned with the "quantum" of fertility, including the issues of anticipating future period and cohort fertility levels as well as population prospects or explaining trends and reversals in fertility. Often, the presumed mismatch between fertility intentions and behaviour is largely a by-product of using period indicators of fertility, where the tempo effect strongly biases both the analysis and the resulting conclusions. Also from the perspective of shorterterm trends and reversals in fertility, most policies that have potential effects on fertility are arguably "quantum-oriented": If, for instance, a new system of parental leave is established, few politicians hoping that it may have a positive and lasting influence on fertility would be content to learn that this influence may vanish after a couple of years, because it would primarily operate through a tempo effect boosting the period TFR.

However, "tempo policies," aiming to stimulate earlier timing of childbearing in order to give a temporary boost to the number of births without necessarily affecting completed fertility, make up a legitimate and potentially useful goal (Lutz) Skirbekk 2005, Rindfuss/Brauner-Otto 2008). These policies in fact constitute an exception, where the TFR could give a useful signal about their effects, although the analysis of trends in total number of births and in tempo-adjusted fertility indicators and parity progression ratios would be equally valuable.

With this exception in mind, these considerations seem to imply that there is indeed little use for the period TFR outside the models constructed by demographers. Still, these considerations are "theoretical" because they are contingent on the availability of a broadly accepted better indicator of period quantum. While there are many useful indicators, we are unable to recommend any one as a "default" indicator of choice, since they are based on different underlying models of behaviour that are not universally accepted (Population 1994) and that may not suit all types of measurement purposes (Ní Bhrolcháin 2007, 2008). Given this situation, a parallel 
use of several indicators, carefully selected on the basis of data availability and also of the research question asked or the policy goal formulated, should be considered (Ní Bhrolcháin 2008). If the aim is to get information on the average childbearing intensity in a given year (the period quantum of fertility), we recommend choosing parity progression ratios, tempo-adjusted PATFR*s or adjusted TFR*s, or other indicators that at least partly reduce the distorting influences of age structure, parity distribution and the tempo effect. Especially the use of duration- and parity-specific fertility measures would provide a much better understanding of policy effects on fertility than the ordinary TFR can offer (Ní Bhrolcháin 1987, 1992, 2008). Recently initiated efforts to collect and compute detailed and unified sets of parity-specific fertility indicators within the framework of the Human Fertility Database (www.humanfertility.org) should make a wider use of such indicators much easier in the future. Ultimately, cohort fertility data are best suited to analyse whether specific policies have had a lasting effect or whether there was a discontinuity in fertility trends among the cohorts that reacted most strongly to the policy changes. While ordinary cohort fertility data, specified by year-of-birth cohorts require a long "waiting time" for each cohort to complete its reproductive history, data for parity cohorts, namely, fertility rates and parity progression ratios specified by duration since last previous birth can reduce this drawback (Breton/Prioux 2005 and Hosseini-Chavoshi et al. 2006 constitute nice recent examples of such analysis). ${ }^{3}$

Our findings on the problematic use and interpretation of the period TFR, which should be avoided where possible, are in agreement with earlier arguments of prominent analysts like Norman Ryder (1990), Máire Ní Bhrolcháin (1992, 2008), Jean-Louis Rallu and Laurent Toulemon (1994b) and John Bongaarts and Griffith Feeney (1998). While we also generally agree with a recent conclusion offered by Neyer and Andersson (2007: 22) who proposed that crude measures of fertility, such as the TFR, cannot serve as appropriate measures of policy effects, we do not fully support their claim that an accurate information on fertility changes following the changes in family policies can only be derived from individual-level data (see also Neyer/Andersson 2008). While this may be true for the study of differential fertility behaviour, a carefully drawn interpretation of a wide range of aggregate level fertility indicators can provide crucial insights into the nature of fertility changes. This enables researchers to draw frequently valid and important causal inferences concerning specific new policies or other social and economic changes (Ní Bhrolcháin/Dyson 2007; Št’astná/Sobotka 2009).

In conclusion, there is a strong case for stopping the use of the period TFR as a one-fits-all fertility indicator which is currently common practice. While demographers are increasingly aware of the pitfalls associated with the period TFR, their continuous reliance on this measure fuels large misperceptions of fertility levels and dynamics among policy makers, the media and the general public. As a minimum

3 Note that in Austria, duration-specific parity progression ratios are regularly computed and published within the Geburtenbarometer project that monitors period fertility trends (see http:// www.oeaw.ac.at/vid/barometer/index.html). 
reporting standard, demographers who still choose to use the period TFR should stop referring to it as the "mean number of children per woman", which it evidently is not. The choice of the most appropriate indicator must depend on the question asked. Since it is hard to think of a real-world question for which the TFR would be the indicator of choice there are good reasons for abandoning it altogether in communications with non-demographic audiences who almost inevitably will misinterpret it as a cohort measure. But such a radical solution may be premature as long as there is no widely accepted and easily available alternative. Hence, for pragmatic reasons, the TFR should remain in use as part of a bouquet of fertility indicators. As the period TFR is most widely available and it often rises and falls in line with other indicators it is still worth being calculated and inspected. But its misleading "cohort" interpretation should be avoided and, wherever possible, more appropriate indicators should be used.

When René Kuczynski first proposed total fertility a century ago at the International Congress on Hygiene and Demography in Berlin in 1907 (see Kuczynski 1932 [1982]) it was a major innovation in fertility research. But at least since 1946, when order-specific fertility indexes controlling for the parity of mothers have been devised by Pascal K. Whelpton, methodologically superior period fertility measures have become available. As in economics, where the use and computations of mainstream measures like the Gross Domestic Product, gets repeatedly revised and questioned (Stiglitz et al. 2009), it is time in demographers to go beyond the period TFR in routine fertility reporting and policy communications. Given that it has become so dear to many cohorts of demographers and data users it would take quite a while for the period TFR to lose its dominant position even if the points made in this article were readily accepted. We hope nevertheless that our study will stimulate a discourse about the best practice of fertility reporting and will contribute to the broader dissemination of different fertility measures which will more accurately inform policy makers and the public at large about the aspects of fertility change that matter for their questions.

\section{Notes and Acknowledgements}

A preliminary draft of this study has been presented at the 2008 annual meeting of the Population Association of America in New Orleans, 17-19 April 2008. We are thankful to the conference participants and to John Bongaarts, Laurent Toulemon, Dimiter Philipov, François Héran, Vegard Skirbekk, Marc Luy and two anonymous reviewers for their comments and suggestions. Many thanks to Werner Richter for language editing. A previous, more extended version is available as a research paper (Sobotka and Lutz 2009).

\section{References}

Alders, Maarten 2000: Cohort fertility of migrant women in the Netherlands. Paper presented at the BSPS-NVD-URU Conference in Utrecht (the Netherlands), 31 August-1 September 2000. 
Andersson, Gunnar 2004: Childbearing after migration: fertility patterns of foreignborn women in Sweden. In: International Migration Review 38,2: 747-775 [doi: 10.1111/j.1747-7379.2004.tb00216.x].

Andersson, Gunnar; Hoem, Jan M.; Duvander, Ann-Zofie 2006: Social differentials in speed-premium effects in childbearing in Sweden. In: Demographic Research 14,4: 51-70 [doi: 10.4054/DemRes.2006.14.4].

Barkalov, Nicholas B.; Dorbritz, Jürgen 1996: Measuring parity-progression ratios with competing techniques. An application to East Germany. In: Zeitschrift für Bevölkerungswissenschaft 21,4: 459-505.

Bongaarts, John 2002: The end of the fertility transition in the developed world. In: Population and Development Review 28,3: 419-443 [doi: 10.1111/j.1728-4457.2002.00419.x].

Bongaarts, John 2008: What can fertility indicators tell us about pronatalist policy options? In: Vienna Yearbook of Population Research 2008: 39-55 [doi: 10.1553/populationyearbook2008s39].

Bongaarts, John; Feeney, Griffith 1998: On the quantum and tempo of fertility. In: Population and Development Review 24,2: 271-291 [doi: 10.2307/2807974].

Bongaarts, John; Feeney, Griffith 2000: On the quantum and tempo of fertility: Reply. In: Population and Development Review 26,3: 560-564 [doi: 10.1111/j.17284457.2000.00560.x].

Bongaarts, John; Feeney, Griffith 2006: The quantum and tempo of life cycle events. In: Vienna Yearbook of Population Research 2006: 115-151 [doi: 10.1553/populationyearbook2006s115].

Bongaarts, John; Sobotka. Tomáš 2010: Demographic explanations for the recent rise in Europe's fertility. Paper presented at the European Population Conference 2010 in Vienna, 2 September 2010.

Breton, Didier; Prioux, France 2005: Two children or three? Influence of family policy and socio-demographic factors. In: Population-E 60,4: 415-445 [doi:10.2307/4148181].

Chesnais, Jean-Claude 2000: Determinants of below-replacement fertility. In: Below replacement fertility. Population Bulletin of the United Nations, Special Issue 40-41: 126-136.

Council of Europe 2006: Recent demographic developments in Europe 2005. Strasbourg: Council of Europe Publishing.

Delgado, Margarita; Meil, Gerardo; Zamora López Francisco 2008: Spain: Short on children and short on family policies. In: Demographic Research, Special collection 7, Vol. 19, Article 27: 1059-1124 [doi: 10.4054/DemRes.2008.19.27].

European Commission 2005: Confronting demographic change: a new solidarity between the generations. Brussels: Commission of the European Communities. [http:// ec.europa.eu/employment_social/news/2005/mar/comm2005-94_en.pdf].

European Commission 2006: Five ways to defuse the demographic time bomb. Press release IP/06/1359 of the European Commission, 12 October 2006. [http://europa.eu/ $\mathrm{rapid} /$ pressReleasesAction.do?reference $=I \mathrm{P} / 06 / 1359]$.

European Parliament 1984: The European parliament on the need for promoting population growth. Resolution No. C127/78. In: Population and Development Review 10,3: 569-570.

European Parliament 2008: European Parliament resolution of 21 February 2008 on the demographic future of Europe (2007/2156 (INI)). Accessed at: [http://www. europarl.europa.eu/sides/getDoc.do?pubRef=-//EP//TEXT+TA+P6-TA-20080066+0+DOC+XML+V0//EN]. 
Eurostat 2003: New Cronos database. Theme 3: Population and social conditions. Accessed in May and October 2003.

Eurostat 2008 and 2010: Population and Social Conditions. [Online database of Eurostat accessed in May 2008 and March 2010 at: http://epp.eurostat.ec.europa.eu].

Eurostat 2009: Population statistics in Europe 2008: first results. Data in Focus, 31/2009. [Available online at: http://epp.eurostat.ec.europa.eu/cache/ITY_OFFPUB/KSQA-09-031/EN/KS-QA-09-031-EN.PDF].

Frejka, Tomas; Sobotka, Tomáš 2008: Fertility in Europe: Diverse, delayed and below replacement. In: Demographic Research, Special Collection 7,19, Article 3: 15-46 [doi: 10.4054/DemRes.2008.19.3].

Gaschke, Susanne 2009: Bilderbuch-Vater. In: Die Zeit, 19 February 2009. [http://zeit. de/2009/09/01-Vaeter].

Gauthier, Anne H. 2007: The impact of family policies on fertility in industrialized countries: a review of the literature. In: Population Research and Policy Review 26: 232-346 [doi: 10.1007/s11113-007-9033-x].

Goldstein, Joshua R.; Sobotka, Tomáś; Jasilioniene, Aiva 2009: The end of lowest-low fertility? In: Population and Development Review 35,4: 663-700 [doi: 10.1111/j.17284457.2009.00304.x].

Héran, François; Pison, Gilles 2007: Two children per woman in France in 2006: are immigrants to blame? In: Population and Societies 432, March 2007 [http://www.ined.fr/ fichier/t telechargement/7659/telechargement fichier_en_publi_pdf2 pop.and.soc. english.432.pdf].

Hoem, Jan M. 1990: Social policy and recent fertility change in Sweden. In: Population and Development Review 16,4: 735-748.

Hosseini-Chavoshi, Meimanat; McDonald, Peter; Abbasi-Shavazi, Mohammad Jalal 2006: The Iranian fertility decline, 1981-1999: An application of the synthetic parity progression ratio method. In: Population-E 61,5-6: 701-718 [doi: 10.3917/pope.605.0701].

INE 2009 and 2010: Movimiento Natural de la Población 2007, 2008. Datos definitivos. Madrid: Instituto National de Estadística. Downloaded in March 2009 and April 2010 at: [http://www.ine.es/jaxi/menu.do?type=pcaxis\&path=/t20/e301/\&file=inebase].

Keyfitz, Nathan 1993: A review of the book by $\mathrm{H}$. Le Bras (Marianne et les lapins: I'obsession démographique). In: Population and Development Review 19,2: 365-374.

Kohler, Hans-Peter; Ortega, José A. 2002: Tempo-adjusted period parity progression measures, fertility postponement and completed cohort fertility. In: Demographic Research 6, Article 6: 92-144 [doi: 10.4054/DemRes.2002.6.6].

Kohler, Hans-Peter; Philipov, Dimiter 2001: Variance effects in the Bongaarts-Feeney formula. In: Demography 38,1: 1-16 [doi: 10.1353/dem.2001.0004].

Kohler, Hans-Peter; Billari, Francesco C.; Ortega, José A. 2002: The emergence of lowest-low fertility in Europe during the 1990s. In: Population and Development Review 28,4: 641-680 [doi: 10.1111/j.1728-4457.2002.00641.x].

Kuczynski, René R. 1932 [1982]: Fertility and Reproduction. Reprinted in 1982. In: Beiträge zur Demographie 6: Berlin (GDR): Akademie-Verlag.

Liefbroer, Aart C. 2009: Changes in family size intentions across young adulthood: A lifecourse perspective. In: European Journal of Population 25,4: 363-386 [doi: 10.1007/ s10680-008-9173-7]. 
Lutz, Wolfgang 2007: Adaptation versus mitigation policies on demographic change in Europe. In: Vienna Yearbook of Population Research 2007: 19-25 [doi: 10.1553/populationyearbook2007s19].

Lutz, Wolfgang; O'Neill, Brian C.; Scherbov, Sergei 2003: Europe's population at a turning point. In: Science 299: 1991-1992 [doi: 10.1126/science.1080316].

Lutz, Wolfgang; Skirbekk, Vegard 2005: Policies Addressing the Tempo Effect in LowFertility Countries. In: Population and Development Review 31,4: 703-725 [doi: 10.1111/j.1728-4457.2005.00094.x].

Lutz, Wolfgang; Skirbekk, Vergard; Testa, Maria Rita 2006: The low fertility trap hypothesis. Forces that may lead to further postponement and fewer births in Europe. In: Vienna Yearbook of Population Research 2006: 167-192 [doi: 10.1553/populationyearbook2006s167].

McDonald, Peter 2006: Low fertility and the state: The efficacy of policy. In: Population and Development Review 32,3: 485-510 [doi: 10.1111/j.1728-4457.2006.00134.x].

Morgan, S. Philip 1981: Intention and uncertainty at later stages of childbearing: The United States 1965 and 1970. In: Demography 18,3: 267-285.

Neyer, Gerda; Andersson, Gunnar 2007: Consequences of family policies on childbearing behavior: Effects or artifacts? In: MPIDR Working Paper WP 2007-021. Rostock: Max Planck Institute for Demographic Research. [http://www.demogr.mpg.de/papers/ working/wp-2007-021.pdf].

Neyer, Gerda; Andersson, Gunnar 2008: Consequences of family policies on childbearing behavior: Effects or artifacts? In: Population and Development Review 34,4: 699-724 [doi: 10.1111/j.1728-4457.2008.00246.x].

Ní Bhrolcháin, Máire 1987: Period parity progression ratios and birth intervals in England and Wales, 1941-1971: A synthetic life table analysis. In: Population Studies 41,1: 103-125.

Ní Bhrolcháin, Máire 1992: Period paramount? A critique of the cohort approach to fertility. In: Population and Development Review 18,4: 599-629.

Ní Bhrolcháin, Máire 2007: Five reasons for measuring period fertility. Working Paper A08/05. University of Southampton: Southampton Statistical Sciences Research Institute.

Ní Bhrolcháin, Máire 2008: Tempo and the TFR. Working Paper A08/10. University of Southampton: Southampton Statistical Sciences Research Institute.

Ní Bhrolcháin, Máire; Dyson, Tim 2007: On causation in demography: Issues and illustrations. In: Population and Development Review 33,1: 1-36 [doi: 10.1111/j.17284457.2007.00157.x].

OECD 2007: Babies and Bosses: Reconciling Work and Family Life. A Synthesis of Findings for OECD Countries. Paris: OECD.

ONS 2007: Birth statistics. Review of the Registrar General on births and patterns of family building England and Wales, 2006. Series FM1 35. London: Office of National Statistics.

Østby, Lars 2002: The demographic characteristics of immigrant populations in Norway. In: Reports 2002/22. Oslo: Statistics Norway.

Park, Chai Bin 1976: Lifetime probability of additional births by age and parity for American women, 1935-1968: A new measurement of period fertility. In: Demography 13,1: 1-17. 
Population 1994: Period fertility measures. Reflective commentaries. In: Population: An English Selection 6,1994: 95-130.

Quesnel-Vallée, Amélie; Morgan, S. Philip 2004: Missing the target? Correspondence of fertility intentions and behavior in the U.S. In: Population Research and Policy Review 22,5-6: 497-525 [doi: 10.1023/B:POPU.0000021074.33415.c1].

Rallu, Jean-Louis; Toulemon, Laurent 1994a: Period fertility measures. The construction of different indices and their application to France, 1946-89. In: Population: An English Selection, 6: 59-94.

Rallu, Jean-Louis; Toulemon, Laurent 1994b: Period fertility measures: The authors' reply. In: Population: An English Selection 6,1994: 123-130.

Rindfuss, Ronald R.; Brauner-Otto, Sarah R. 2008: Institutions and the transition to adulthood: Implications for fertility tempo in low fertility settings. In: Vienna Yearbook of Population Research 2008: 57-87 [doi: 10.1553/populationyearbook2008s57].

Ryder, Norman 1990: What is going to happen to American fertility? In: Population and Development Review 16,3: 433-454.

Schoen, Robert 2004: Timing effects and the interpretation of period fertility. In: Demography 41,4: 801-819 [doi: 10.1353/dem.2004.0036].

Smallwood, Steve; Jefferies, Julie 2003: Family building intentions in England and Wales: trends, outcomes and interpretations. In: Population Trends 112 (Summer 2003): 15-25.

Sobotka, Tomáš 2004a: Is lowest-low fertility explained by the postponement of childbearing? In: Population and Development Review 30,2: 195-220 [doi: 10.1111/j.17284457.2004.010_1.x].

Sobotka, Tomáš 2004b: Postponement of childbearing and low fertility in Europe. PhD Thesis, University of Groningen. Amsterdam: Dutch University Press.

Sobotka, Tomáš 2008: The rising importance of migrants for childbearing in Europe. In: Demographic Research, Special Collection 7, 19,9: 225-248 [doi: 10.4054/ DemRes.2008.19.9.]

Sobotka, Tomáš 2009: Subreplacement fertility intentions in Austria. In: European Journal of Population 25,4: 387-412 [doi: 10.1007/s10680-009-9183-0.]

Sobotka, Tomáš; Lutz, Wolfgang 2009: Misleading policy messages from the period TFR: Should we stop using it? In: European Demographic Research Papers 2009-4. Vienna: Vienna Institute of Demography. [http://www.oeaw.ac.at/vid/download/edrp_4_09. pdf].

Sobotka, Tomáš et al. 2005: Monthly Estimates of the Quantum of Fertility: Towards a Fertility Monitoring System in Austria. In: Vienna Yearbook of Population Research 2005: 109-141 [doi: 10.1553/populationyearbook2005s109].

Sobotka, Tomáš; Štastná, Anna; Zeman, Kryštof; Hamplová, Dana; Kantorová, Vladimíra 2008: Czech Republic: A rapid transformation of fertility and family behaviour. In: Demographic Research, Special collection 7, 19,14: 403-454 [doi: 10.4054/ DemRes.2008.19.14].

Špidla, Vladimír 2007: Introduction by Commissioner Vladimír Špidla to the four essays written in response to the communication on The Demographic Future of Europe. In: Vienna Yearbook of Population Research 2007: 1-3 [doi: 10.1553/populationyearbook2007s1].

Statistics Denmark 2007: Befolkningens udvikling 2006. Vital statistics 2006. Statistics Denmark, Copenhagen. 
Stiglitz, Joseph E; Sen, Amartya; Fitoussi, Jean-Paul 2009: Report by the commission on the measurement of economic performance and social progress. URL: [http:// www.stiglitz-sen-fitoussi.fr/en], 24-10-2009.

Štastná, Anna; Sobotka, Tomáš 2009: Changing parental leave and shifts in second and third-birth rates in Austria. VID Working paper 07/2009: Vienna: Vienna Institute of Demography. URL: [http://www.oeaw.ac.at/vid/download/WP2009_07.pdf].

Testa, Maria Rita 2006: Childbearing preferences and family issues in Europe. Special Eurobarometer 253/Wave 65.1 - TNS Opinion \& Social: European Commission.

Testa, Maria Rita 2007: Childbearing preferences and family issues in Europe: Evidence from the Eurobarometer 2006 survey. In: Vienna Yearbook of Population Research 2007: 357-379 [doi: 10.1553/populationyearbook2007s357].

Toulemon, Laurent 2004: Fertility among immigrant women: new data, new approach. In: Population \& Societies 400 (April 2004): 1-4. URL: [http://www.ined.fr/fichier/t publication/540/publi_pdf2_pop_and_soc_english_400.pdf].

Toulemon, Laurent; Leridon; Henri 1999: La famille idéale: combien d'enfants, à quel âge? [Ideal family: How many children, at what age?] In: INSEE Premiere 652, June 1999.

Toulemon, Laurent; Mazuy, Magali 2004: Comment prendre en compte l'âge à l'arrivée et la durée de séjour en France dans la mesure de la fécondité des immigrants? [How to consider jointly age at arrival and duration of stay in France in the measures of immigrants' fertility?] In: Documents de travail 120. Paris: INED.

Van Imhoff, Evert 2001: On the impossibility of inferring cohort fertility measures from period fertility measures. In: Demographic Research 5,2: 23-64 [doi: 10.4054/ DemRes.2001.5.2].

VID 2010: European demographic data sheet 2010. Vienna Institute of Demography and IIASA. URL: [http://www.oeaw.ac.at/vid/datasheet/download_2010.shtml].

Westoff, Charles F.; Ryder, Norman B. 1977: The predictive validity of reproductive intentions. In: Demography 14,4: 431-453.

Whelpton, Pascal K. 1946: Reproduction rates adjusted for age, parity, fecundity, and marriage. In: Journal of the American Statistical Association 41: 501-516.

Zakharov, Sergei 2006: Демографический анализ эффеекта мер семейной политики в 1980-х годах. [Demographic analysis of the effect of family policy measures in Russia in the 1980s]. In: SPERO 4-5: 33-69. URL: [http://spero.socpol.ru/docs/N5_2006-33_69. pdf].

Zakharov, Sergei 2008: Russian Federation: From the first to second demographic transition. In: Demographic Research, Special Collection 7,19, Article 24: 907-972 [doi: 10.4054/DemRes.2008.19.24].

Tomáš Sobotka ( $\square)$, Wolfgang Lutz

Vienna Institute of Demography of the Austrian Academy of Sciences, Wittgenstein Centre for Demography and Global Human Capital

E-Mail: tomas.sobotka@oeaw.ac.at, wolfgang.lutz@oeaw.ac.at 
662 • Tomáš Sobotka, Wolfgang Lutz

A German translation of this reviewed and authors' authorised original article by the Federal Institute for Population Research is available under the title "Wie Politik durch falsche Interpretationen der konventionellen Perioden-TFR in die Irre geführt wird: Sollten wir aufhören, diesen Indikator zu publizieren?", DOI 10.4232/10.CPoS-15de or URN urn:nbn:de:bib-cpos-2010-15de1, at http://www. comparativepopulationstudies. de.

Date of submission: 23.07.2010

Date of acceptance: 07.10 .2010 


\section{Appendix: Fertility indicators used in this study}

Besides the period and cohort total fertility rates, specified separately for first births and for total birth orders, this study uses the following indicators of period fertility:

Tempo-adjusted total fertility (TFR*), developed by Bongaarts and Feeney (1998), is computed as a sum of order-specific adjusted TFR*s, which take order-specific changes in the mean age of fertility schedule as an adjustment factor:

$T F R_{i}(t)^{*}=T F R_{i}(t) /\left(1-r_{i}(t)\right)$,

where $r_{i}(t)$ is the estimated change in the mean age at childbearing of birth order $i$ between the beginning and the end of year $t$. Following Bongaarts and Feeney (2000: 563, fn. 1 ), this is estimated as follows:

$r_{i}(t)=\left[M A B_{i}(t+1)-M A B_{i}(t-1)\right] / 2$,

where $M A B_{i}(t)$ is the mean age of fertility schedule of order $i$, calculated from age-specific fertility rates by birth order (incidence rates which do not control for parity distribution). Since the $T F R^{*}$ displays considerable annual fluctuations, threeyear moving averages are used in this study.

Fertility index controlling for age and parity (PATFR) is computed from a set of age and parity-specific birth probabilities, $q_{i}(a)$, which serve as an input of multistate fertility tables (e.g. Park 1976). Following Rallu and Toulemon (1994a: 66), orderspecific birth probabilities are computed directly from the annual data on live births by age of mother (a) and birth order (i) combined with the parity and age structure of the female population at the beginning of a given year:

$q_{i}(a, t)=B_{i}(a, t) / P_{F, i-1}(a, T=$ January 1 of $t)$.

This equation expresses the probability that a woman aged $a$ and having $i-1$ children at the beginning of a year $t$ will give birth during the year. For more details of the computations used, see Sobotka (2004b: 44-46 and 92-93). For further information on age and parity-specific fertility index and its computation, see Park (1976), Rallu and Toulemon (1994a) and Barkalov and Dorbritz (1996).

Tempo and variance-adjusted period fertility index controlling for age and parity (PATFR*).

This modification of the PATFR index was proposed by Kohler and Ortega (2002). Their method provides an estimation of period fertility that is free of three distortions present in the TFR, namely distortions caused by (1) changes in the parity distribution of women, (2) changes in fertility timing and (3) changes in the variance of the fertility schedule. It is an analogy of the method developed first by Kohler and Philipov (2001) for an adjustment of age-specific fertility rates of the second 
664 • Tomáš Sobotka, Wolfgang Lutz

kind (incidence rates), specified by birth order. The authors employ a procedure that iteratively corrects the observed mean age and the inferred tempo change for distortions caused by the variance effects (Kohler/Philipov 2001: 10). We employ a simplified version of this adjustment, which is described in Sobotka (2004b: 94). As in the case of $T F R^{*}$, we use three-year moving averages of the PATFR* ${ }^{*}$ to reduce random fluctuations in this index. 


\section{Comparative Population Studies - Zeitschrift für Bevölkerungswissenschaft}

www.comparativepopulationstudies.de

ISSN: 1869-8980 (Print) - 1869-8999 (Internet)

Published by / Herausgegeben von

Prof. Dr. Norbert F. Schneider

Layout and print: Federal Institute for Population Research, Wiesbaden (Germany)

Managing Editor / Redaktion

Frank Swiaczny

\section{Copy Editor / Schlussredaktion}

Dr. Evelyn Grünheid

\section{Scientific Advisory Board / Wissenschaftlicher Beirat}

Jürgen Dorbritz (Wiesbaden)

Paul Gans (Mannheim)

Johannes Huinink (Bremen)

Marc Luy (Wien)

Clara H. Mulder (Groningen)

Notburga Ott (Bochum)

Peter Preisendörfer (Mainz)

\section{Board of Reviewers / Gutachterbeirat}

Martin Abraham (Erlangen)

Laura Bernardi (Lausanne)

Hansjörg Bucher (Bonn)

Claudia Diehl (Göttingen)

Andreas Diekmann (Zürich)

Gabriele Doblhammer-Reiter (Rostock)

Henriette Engelhardt-Wölfler (Bamberg)

E.-Jürgen Flöthmann (Bielefeld)

Alexia Fürnkranz-Prskawetz (Wien)

Beat Fux (Zürich)

Joshua Goldstein (Rostock)

Karsten Hank (Mannheim)

Sonja Haug (Regensburg)

Franz-Josef Kemper (Berlin)

Michaela Kreyenfeld (Rostock)

Aart C. Liefbroer (Den Haag)

Kurt Lüscher (Konstanz)

Dimiter Philipov (Wien)

Tomáš Sobotka (Wien)

Heike Trappe (Rostock) 